\title{
A Vibration-Isolating Blast Technique with Shock-Reflection Device for Dam Foundation Excavation in Complicated Geological Conditions
}

\author{
Haoran Hu (iD, ${ }^{1,2}$ Wenbo Lu (iD, ${ }^{1,2}$ Peng Yan, ${ }^{1,2}$ Ming Chen, ${ }^{1,2}$ and Qidong Gao ${ }^{1,2}$ \\ ${ }^{1}$ State Key Laboratory of Water Resources and Hydropower Engineering Science, Wuhan University, Wuhan, Hubei 430072, China \\ ${ }^{2}$ Key Laboratory of Rock Mechanics in Hydraulic Structure Engineering of Ministry of Education, Wuhan University, Wuhan, \\ Hubei 430072, China
}

Correspondence should be addressed to Wenbo Lu; wblu@whu.edu.cn

Received 7 February 2018; Revised 15 May 2018; Accepted 17 May 2018; Published 27 June 2018

Academic Editor: Georges Kouroussis

Copyright @ 2018 Haoran Hu et al. This is an open access article distributed under the Creative Commons Attribution License, which permits unrestricted use, distribution, and reproduction in any medium, provided the original work is properly cited.

\begin{abstract}
Under complicated geological conditions, the vibration in the dam foundation caused by blasting can lead to further deterioration of the foundation rock mass and adversely affect the safety of foundation. In order to effectively control the vibration in dam foundation rock mass, a new bench blasting technique with shock-reflection device is proposed. It introduces a shock-reflection device consisting of high wave impedance block and cushion material, which is placed at the bottom of vertical borehole. This shockreflection device can effectively reflect the explosion shock wave from vertical direction to horizontal direction after detonation, which can make blasting energy concentrated on the rock mass above dam foundation, so the vibration in the foundation can be controlled. Field blasting experiment was carried out to contrast the blasting induced vibration in foundation rock by bench blasting with shock-reflection device and conventional bench blasting. The results indicate that the vibration in the foundation rock can be reduced by $30 \% \sim 57 \%$. In addition, the vibration at the bottom of the borehole is also demonstrated by numerical simulation, with results similar to the field experiments. The production experiment results show that the new blasting technique can replace the conventional excavation method of dam foundation in complicated geological conditions, and the new blasting technique has been successfully applied to the Baihetan dam foundation excavation.
\end{abstract}

\section{Introduction}

The energy released by the explosives during the blasting process is not completely used by the rock mass fragment, a large part of which will induce vibration of the retained rock mass $[1,2]$ and inevitably influence its internal structure. When the vibration speed exceeds the allowable value, it can induce cracks and potentially affect the safety of the rock mass [3]. Therefore, in the excavation process of dam foundation or slope, much attention needs to be paid to the vibration control [4].

There is mainly columnar jointed basalt below altitude of 600 meters at the right bank dam foundation of Baihetan Hydropower Station. The columnar jointed basalt is a typical rock that is originated from lava flow and contains many joints cutting the original intact rocks into regular or irregular columnar blocks. Serving as its typical feature during blasting excavation, multiple stress wave reflections occur under the action of dynamic load due to existence of rock joints within the columnar jointed basalt, which may result in dynamic tension failure and then lead to the fracture of the joint surface. If blast-induced cracks occur, developing and converging with each other, the columnar jointed basalt will lose its bearing capacity $[5,6]$. Another typical characteristic of columnar jointed basalt is that, after excavation, the pillars will gradually detach from each other and relaxation occurs, as shown in Figure 1.

In order to ensure the dam foundation excavation quality of the columnar jointed basalt under complicated geological conditions at Baihetan, it firstly requires reducing the explosion stress to avoid the columnar joint failure during the blasting process. Then rapid excavation is needed to 


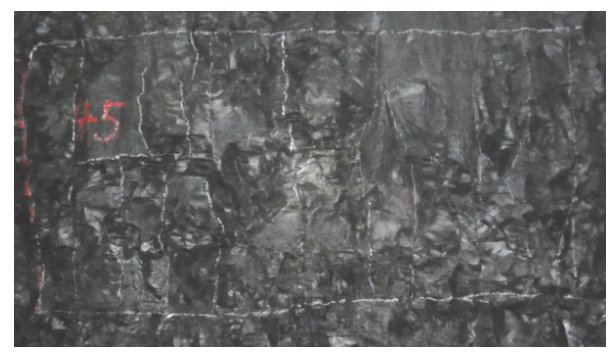

(a) Original

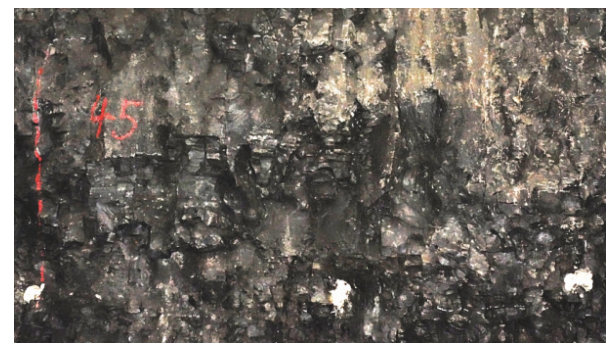

(b) Relaxed

FIGURE 1: Columnar jointed basalt found in Baihetan Hydropower Station.

avoid relaxation phenomenon. Many research results show that inner structure failure of rock mass is caused by the stress waves. When dynamic stress and strain caused by the stress wave exceed the allowable value, rock failure will occur. Because of the close relationship between PPV (peak particle velocity) and dynamic stress (and strain), it can be used as the control parameter for excavation of columnar jointed basalt [7-9]. Therefore, the way to guarantee safety of Baihetan dam foundation excavation actually comes to strictly controlling the PPV inside the rock mass under the premise of rapid excavation.

According to Chinese construction technical specification and practical experience in engineering practice, the commonly used methods for dam foundation excavation include traditional layered blasting, presplitting blasting, and smooth blasting [10]. Traditional layered blasting can effectively control the blasting vibration, but the construction schedule can be significantly delayed due to excessive layers. The presplitting cracks formed by the presplitting borehole effectively isolate the stress wave induced by production borehole in presplitting blasting technique; the blasting scale is usually small and the charging parameters of each borehole are strictly limited, so vibration inside the dam foundation can be well controlled. As smooth blasting and presplitting blasting require pioneer plots and working faces, it involves complex operations to drill contour boreholes, leading to low construction efficiency [10]. During the dam foundation excavation process of the Three Gorges Hydropower Station, the above-mentioned three kinds of excavation methods were used in combination, resulting in a period of 1.5 months lagging behind schedule [11].

In order to find a suitable excavation method for dam foundation excavation under Baihetan complicated geological conditions, the bench blasting with cushion at borehole bottom (BC) has been improved: a shock-reflection device is installed at the vertical borehole bottom to control blasting vibration. Numerical simulation and field experiments are presented in this study to compare the vibration induced by bench blasting with shock-reflection device (BSR) and $\mathrm{BC}$. The production experiments are used to compare the actual excavation results of BSR and presplitting (smooth blasting), and the BSR has been applied in blasting excavation of the Baihetan dam foundation and exerted good effect in blasting vibration control.

\section{Bench Blasting with Shock-Reflection Device (BSR)}

In order to control the vibration in dam foundation rock mass and get a smooth foundation excavation surface, the bench blasting with cushion at borehole bottom (BC) was proposed and applied to produce dam foundation excavation protective layer. The typical blasting geometry for BC is showed in Figure 2 [10]. The schematic diagram of stress wave interaction on the interface of explosive and cushion is shown in Figure 3. The cushion material used in BC is usually low sonic impedance material, for example, coarse sand, sawdust, rock debris, polyethylene foam, bamboo tube, and wood.

According to the transmission and reflection theory of stress wave, the sonic impedance of two mediums on either side of the interface plays an important role in the intensity of transmitted and reflection wave. Take it as an example that one-dimensional incident wave enters vertically. When the stress wave incomes vertically from media A to media $B$, the reflection and transmission of stress waves acting on different media surface can be expressed by (1) and (2), respectively [12].

$$
\begin{gathered}
R=\frac{\rho_{b}\left(C_{p}\right)_{b}-\rho_{a}\left(C_{p}\right)_{a}}{\rho_{a}\left(C_{p}\right)_{a}+\rho_{b}\left(C_{p}\right)_{b}} I \\
T=\frac{2 \rho_{b}\left(C_{p}\right)_{b}}{\rho_{a}\left(C_{p}\right)_{a}+\rho_{b}\left(C_{p}\right)_{b}} I
\end{gathered}
$$

where $\rho$ is the material density, $C_{p}$ is the $\mathrm{P}$ wave propagation velocity in the material, $\rho C_{p}$ is the material sonic impedance, $I$ is the incoming wave intensity, $R$ is the reflection wave intensity, and $T$ is the transmitted wave intensity.

Since the sonic impedance of the cushion material is less than that of the explosion products, according to (2), the intensity of the stress transmitted into the cushion is small. The theoretical consequence is that the stress wave acting on the foundation rock mass is reduced, and the vibration within the dam foundation is controlled.

However, in practical engineering application, it is found that the cushion material easily fails due to compressed failure or carbonization under explosion-induced high temperature. In this paper, the $\mathrm{BC}$ method has been improved; a high sonic impedance block is placed over the cushion material, serving as a shock-reflection device, as shown in Figure 4.

The shock-reflection device consists of high sonic impedance block and cushion material. It can choose high 
TABLE 1: The intensity of transmission and reflection wave at the interface.

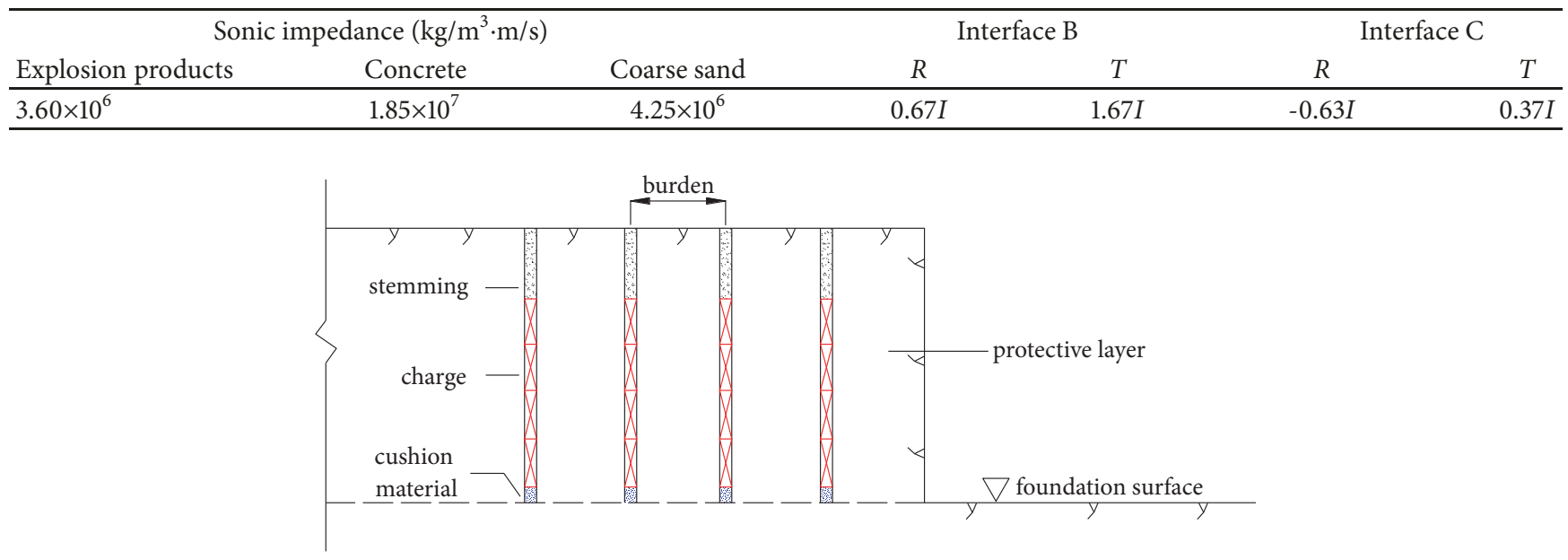

FIgURE 2: Profile of blasting geometry for BC.

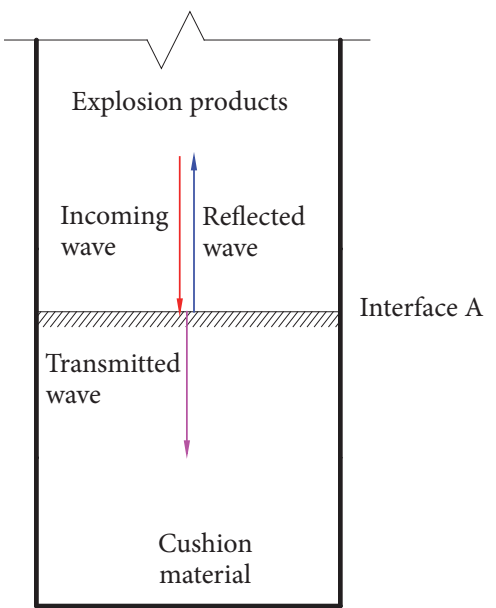

Figure 3: Schematic diagram of stress wave interaction on the interface.

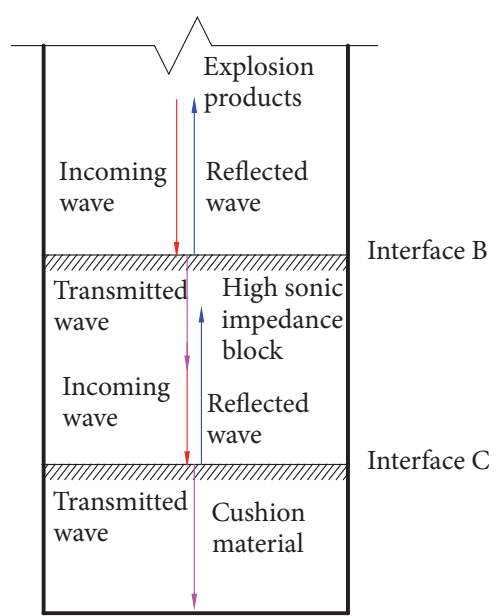

FIGURE 4: The shock-reflection device and stress wave interaction on the interface. sonic impedance concrete or cast iron as the block material [13] and coarse sand as the cushion material, while the cushion material is the same as that used in the BC method.

In the borehole with the shock-reflection device, if the block material uses the high sonic impedance concrete, the cushion material chooses the coarse sand and the intensity of transmission and reflection wave at each interface can be calculated by (1) and (2), and T and R are shown in Table 1. It can be seen that the reflection wave is different, and it is a reflection loading condition at interface $\mathrm{B}$, while it is reflection unloading condition at interface $\mathrm{C}$. The transmitted wave at interface $B$ is the income wave at interface $C$ if the attenuation of stress amplitude is ignored. Therefore, stress amplitude of transmitted wave is $62 \%$ of the initial income stress wave amplitude. After dissipation caused by the large deformation buffer material, only a minimal stress amplitude of transmitted wave transmitted into the foundation rock mass, thus the blasting induced vibration will be small.

Another important requirement in dam foundation excavation process is that the dam foundation excavation surface should be smooth enough, so the reflected wave at interface $\mathrm{B}$ can be directed toward the borehole wall. And the reflected stress wave will strengthen the crushing effect of the rock mass between the boreholes and reduce the rock root between them, which will be helpful for obtaining a smooth dam foundation surface. Therefore, the block is shaped into sphere, which is also more convenient to be installed inside boreholes. The schematic diagram of stress wave interaction on the interface is shown in Figure 5.

The typical blasting geometry for BSR is showed in Figure 6. In order to reduce the rock root, the spherical center of the block should be in the dam foundation surface.

\section{Blasting Vibration Experiments to Verify the New Technique}

3.1. Experiment Design. In order to verify the theory described above, a field experiment was carried out at the 
TABLE 2: Drilling and blasting parameters of the experiment.

\begin{tabular}{lcccccc}
\hline Borehole diameter & Hole depth & Spacing & Charge diameter & Charge length & Charge weight & Stemming length \\
\hline $100 \mathrm{~mm}$ & $6.0 \sim 6.3 \mathrm{~m}$ & $3.5 \mathrm{~m}$ & $32 \mathrm{~mm}$ & $4.5 \mathrm{~m}$ & $4.5 \mathrm{~kg}$ & $1.5 \mathrm{~m}$ \\
\hline
\end{tabular}

TABLE 3: Summary of PPV and vibration reduction factor.

\begin{tabular}{|c|c|c|c|c|c|c|}
\hline \multirow{2}{*}{ Location of detector } & \multicolumn{3}{|c|}{ Top ignition $(\mathrm{cm} / \mathrm{s})$} & \multicolumn{3}{|c|}{ Bottom ignition $(\mathrm{cm} / \mathrm{s})$} \\
\hline & B (Without) & A (With) & $\eta_{p p v}$ & D (Without) & C (With) & $\eta_{p p v}$ \\
\hline $1 \#(1.0 \mathrm{~m})$ & 32.50 & 18.37 & $43.5 \%$ & 33.35 & 14.51 & $56.5 \%$ \\
\hline $2 \#(1.5 \mathrm{~m})$ & 34.40 & 19.21 & $44.2 \%$ & 21.47 & 11.09 & $48.3 \%$ \\
\hline $3 \#(2.0 \mathrm{~m})$ & 27.55 & 19.33 & $29.8 \%$ & 14.07 & 7.92 & $43.7 \%$ \\
\hline
\end{tabular}

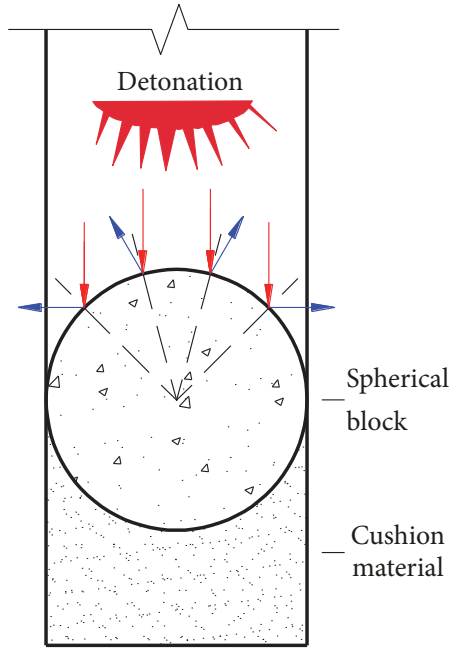

FIGURE 5: The shock-reflection device and stress wave interaction on the interface.

Baihetan Hydropower Station, Jin-sha River. Foundation of downstream plunge pool was selected as the field experiment site near the subsidiary dam. The rock mass here is intact Permian basalts.

As shown in Figure 7, in this blasting experiment, four vertical boreholes and a vibration monitoring hole were drilled. The boreholes were arranged in quadrate with 3.5 $\mathrm{m}$ side length, and the vibration monitoring hole was at the center of quadrate. These boreholes were $100 \mathrm{~mm}$ in diameter and $6.0 \sim 6.3 \mathrm{~m}$ in depth including $1.5 \mathrm{~m}$ for stemming and 4.5 $\mathrm{m}$ for charge. Detailed drilling and blasting parameters are listed in Table 2, and the typical charging structure is plotted in Figure 8. The spherical block used in the experiment is made of high sonic impedance concrete with diameter of 82 $\mathrm{mm}$ (as shown in Figure 9), and the cushion material is coarse sand.

The vibration in the rock mass below the bench floor can be easily recorded by professional equipment. Three vertical vibration sensors were placed in the vibration monitoring hole, arranged at $1.0 \mathrm{~m}, 1.5 \mathrm{~m}$, and $2.0 \mathrm{~m}$ below the bench floor, respectively, as shown in Figure 10. The sensors were fixed by high-strength mortar, so it could accurately measure the internal vibration. The vertical vibration sensor CDJ28 used in this experiment was produced by Chongqing Geological Instrument Factory, which can catch the vibration waveform vertically. The blasting vibration intelligent monitor TC-4850 used in this experiment has a specially designed frequency to cover all the possibilities of blast vibration recording and the sampling interval was 0.0625 milliseconds.

3.2. Experiment Results. According to the blasting field experiment design, the shock-reflection device is arranged at the bottom of boreholes $\mathrm{A}$ and $\mathrm{C}$, with none in boreholes $\mathrm{B}$ and $\mathrm{D}$. The blasting vibration amplitude reduction effect can be seen by comparing the differences of vibration amplitude between the borehole with and without the shock-reflection device.

The recorded original blast-induced vertical velocitytime histories of monitoring were plotted in Figure 11, and the PPV of each delay is shown in Table 3. Here it defines a vibration reduction factor:

$$
\eta_{p p v}=\left(1-\frac{P P V_{\text {with }}}{P P V_{\text {without }}}\right) \times 100 \%
$$

where $P P V_{\text {with }}$ is the PPV of the borehole with the device; $P P V_{\text {without }}$ is the PPV of the borehole without the device; $\eta_{p p v}$ shows the blasting vibration amplitude reduction after adopting the bench blasting with shock-reflection device.

From Table 3, it can be seen that the PPV vertically induced by borehole with the shock-reflection device is much smaller than that without the device, with vibration reduction factor varying from $29.8 \%$ to $56.5 \%$, which indicates the obvious vibration reduction effect of the device. At the same time, when the ignition point is located at the bottom of the hole, the vibration reduction rate will be greater, and the effect of the shock-reflection device will be more significant. Compared with the operating conditions of the same charge structure type, the position of ignition point has a significant impact on PPV. The PPV induced by top ignition borehole is much larger than the bottom ignition borehole. Based on the above results, using the shock-reflection device and putting the detonator at the borehole bottom can effectively control blasting vibration inside the dam foundation rock mass. 


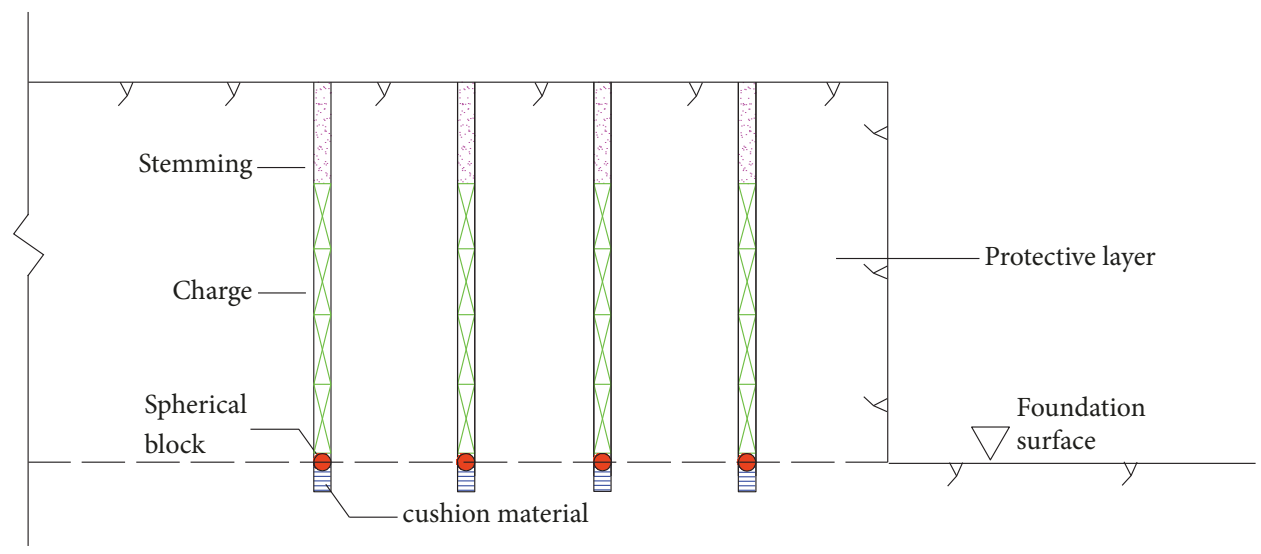

FIGURE 6: Profile of blasting geometry for BSR.

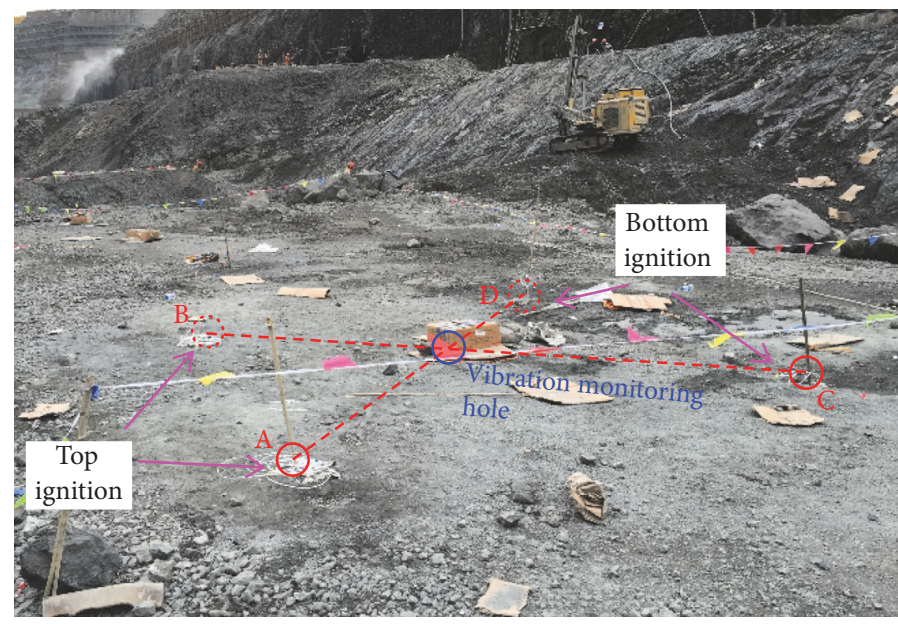

$\cdots$ Without the device

With the device

FIGURE 7: Arrangement of borehole and monitoring holes.

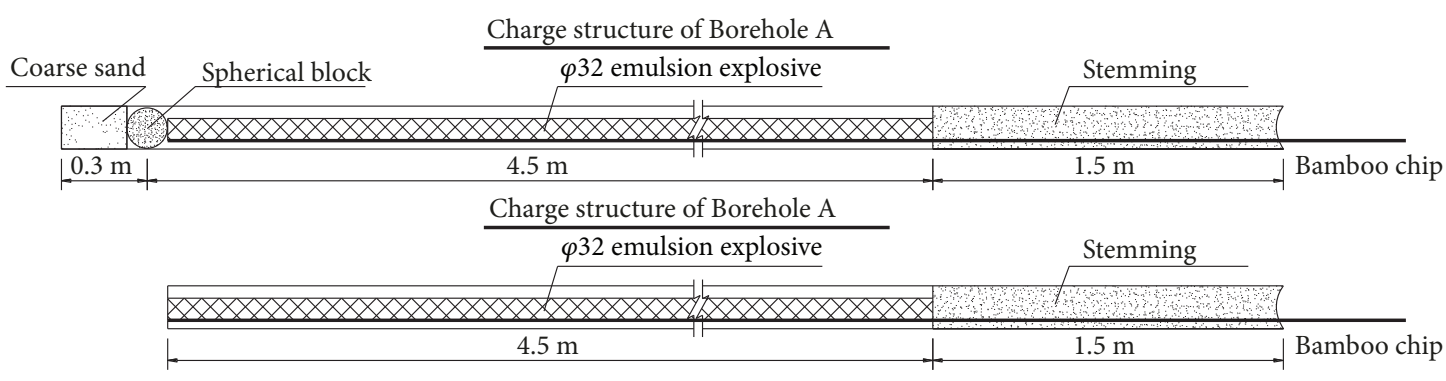

FIGURE 8: Typical charge structure.

\section{Numerical Simulation of a Single Vertical Borehole}

The field experiment verifies the effect of BSR on controlling the vibration velocity inside the dam foundation, while more vibration characteristics inside the dam foundation can be obtained by numerical simulation.
4.1. Numerical Model and Material Parameters. In order to verify the vibration reduction effect of BSR, the ANSYA/LSDYNA software was employed to build up the finite model, as shown in Figure 12. The borehole is $100 \mathrm{~mm}$ in diameter and $6 \mathrm{~m}$ in depth including $1.5 \mathrm{~m}$ for stemming. The diameter of emulsion explosive cartridges is $32 \mathrm{~mm}$, and the spherical block, made of high sonic impedance concrete, is $86 \mathrm{~mm}$ in 
TABLE 4: Material mechanics parameters of rock and concrete in damage model.

\begin{tabular}{lccccccc}
\hline Material & $\begin{array}{c}\text { Density } \\
\left(\mathrm{kg} / \mathrm{m}^{3}\right)\end{array}$ & $\begin{array}{c}\text { Elasticity } \\
\text { modulus }(\mathrm{GPa})\end{array}$ & $\begin{array}{c}\text { Poisson's } \\
\text { ratio }\end{array}$ & $\begin{array}{c}\text { Dynamic tensile } \\
\text { strength }(\mathrm{MPa})\end{array}$ & $\begin{array}{c}\text { Fracture } \\
\text { toughness } \\
\mathrm{K}_{\mathrm{IC}} \\
\left(\mathrm{MN} \times \mathrm{m}^{-3 / 2}\right)\end{array}$ & $\begin{array}{c}\text { Damage } \\
\text { constant } \lambda \\
(\mathrm{Kg} / \mathrm{J})\end{array}$ \\
\hline Rock & 2700 & 15.0 & 0.23 & 3.0 & 0.92 & 0.0001 \\
\hline Concrete & 4107 & 54.3 & 0.18 & 12.8 & 0.9 & 0.0001 \\
\hline
\end{tabular}

TABLE 5: JWL equation of state parameters of the explosive used.

\begin{tabular}{lcccccccc}
\hline Density $\left(\mathrm{kg} / \mathrm{m}^{3}\right)$ & VOD $(\mathrm{m} / \mathrm{s})$ & $P_{C J}(\mathrm{GPa})$ & $A(\mathrm{GPa})$ & $B(\mathrm{GPa})$ & $R_{1}$ & $R_{2}$ & $\omega$ & $E_{0}(\mathrm{GPa})$ \\
\hline 1050 & 4200 & 4.63 & 209.69 & 3.51 & 5.76 & 1.29 & 0.39 & 2.39 \\
\hline
\end{tabular}
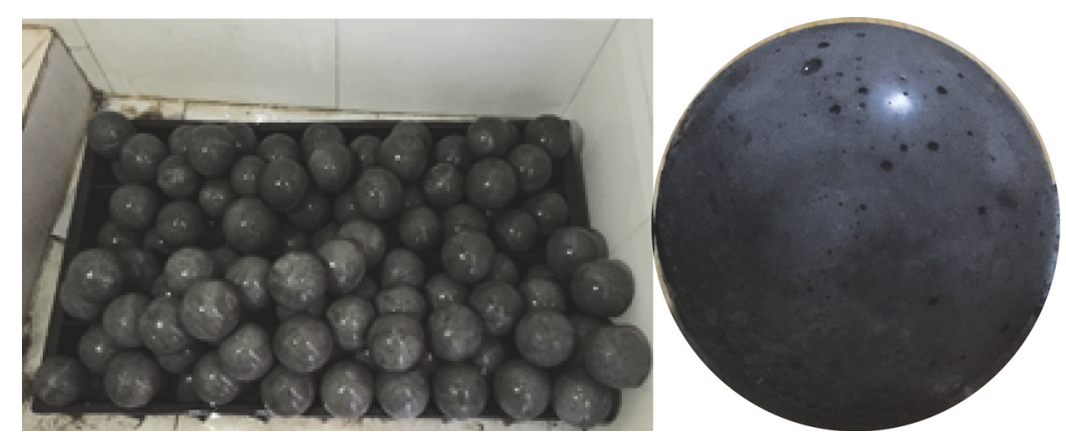

FIGURE 9: Spherical block made of high sonic impedance concrete.

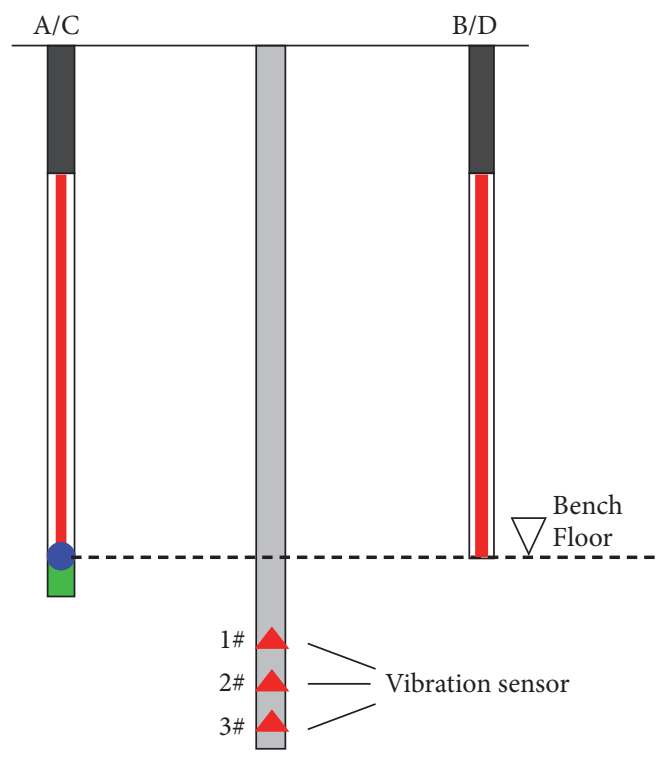

FIgURE 10: Arrangement of vibration sensors.

diameter. It should be pointed out that this numerical model presents the blasting condition in semi-infinite rock mass, and, because of its symmetry, a quarter model is established using the symmetric boundary. Therefore, $\mathrm{X}=0$ and $\mathrm{Y}=0$ plane are set to the symmetrical plan. $X=4.5 \mathrm{~m}$; $Y=4.5 \mathrm{~m}$; and $Z=14 \mathrm{~m}$ plane are set to the no reflection boundary to prevent the effects of reflected waves at edge of the region.
According to the field experiment results, the ignition point is located at the bottom of the hole, $15 \mathrm{~cm}$ above the charge structure bottom.

As the blasting induced damage around the borehole will affect the characteristics of blasting vibration, in order to obtain a more ideal vibration waveform, the tensile-compress damage model, established by $\mathrm{Hu}[14]$, is adopted in this calculation, and the rock damage area calculated by this model is in good agreement with the field experiments. The damage characteristics of high sonic impedance concrete resemble rock material, so the tensile-compress damage model is also used to calculate its damage characteristics. The material mechanics parameters of rock and concrete are shown in Table 4. Related parameter definitions can be found in [14].

The widely used Jones-Wilkens-Lee (JWL) equation of state (EOS) is adopted to describe the relationship between volume, energy, and pressure of detonation products, as expressed in

$$
P=A\left(1-\frac{\omega}{R_{1} V}\right) e^{-R_{1} V}+B\left(1-\frac{\omega}{R_{2} V}\right) e^{-R_{2} V}+\frac{\omega E}{V}
$$

where $P$ is the detonation pressure; $V$ is the relative volume of detonation products; $E$ is the internal energy with an initial value of $E_{0} ; A, B, R_{1}, R_{2}$, and $\omega$ are parameters related to explosive types. The 2 \# rock emulsion explosive was adopted in the simulation, and related parameters refer to the work of Sanchidrian et al. [15], as listed in Table 5, where $D$ is the explosive velocity of detonation (VOD) and PCJ is the Chapman-Jouguet pressure. 


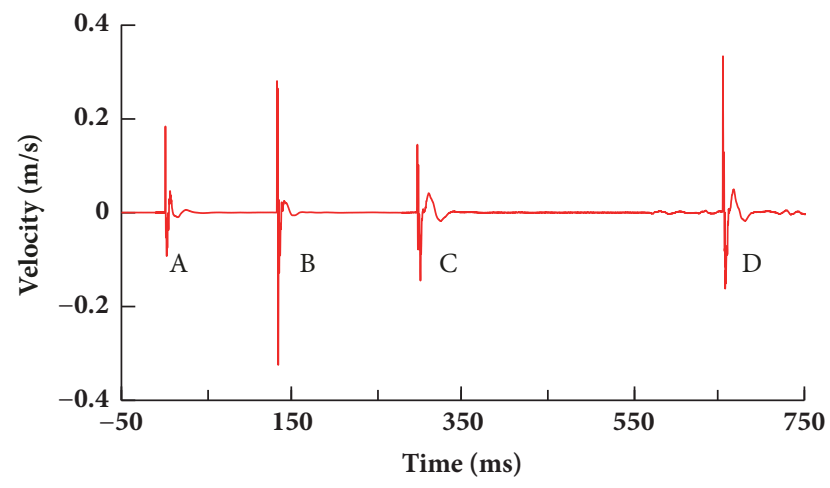

(a) 1\# vibration sensor

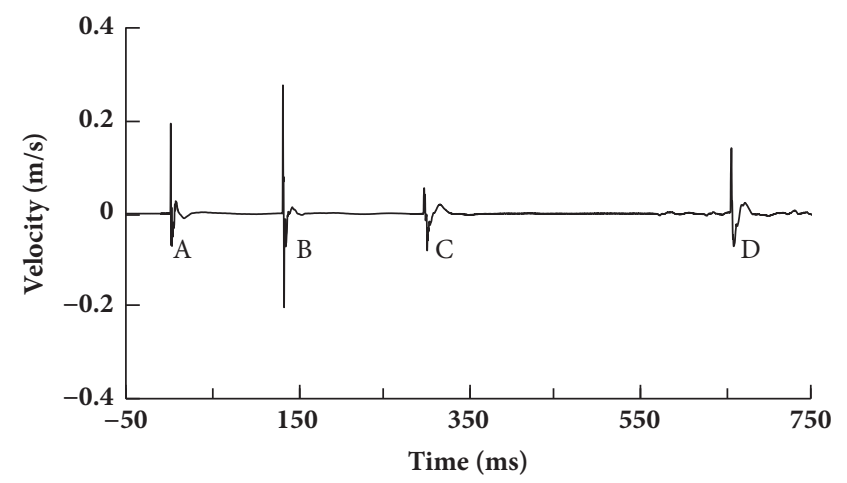

(c) 3\# vibration sensor

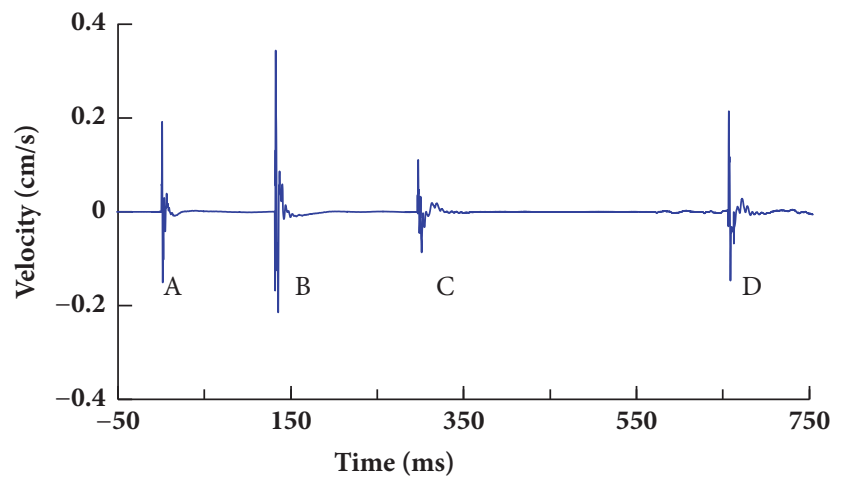

(b) 2\# vibration sensor

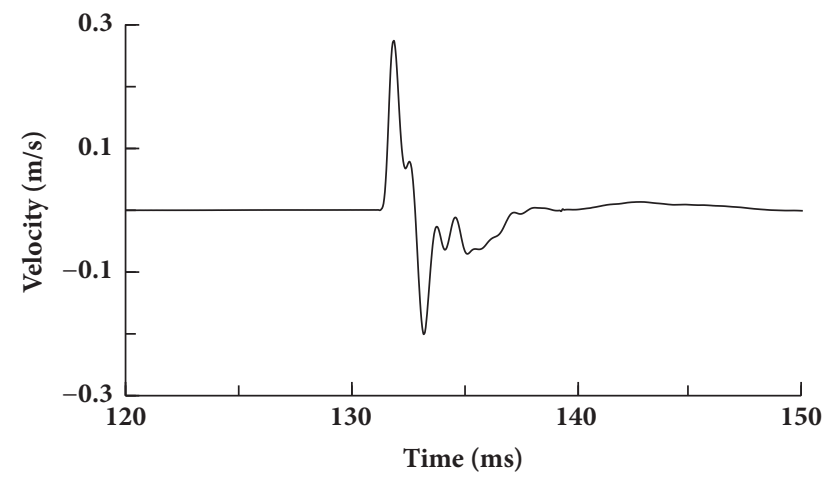

(d) The wave of second delay in (c)

FIGURE 11: Blast-induced vertical velocity-time histories recorded by TC- 4850 .

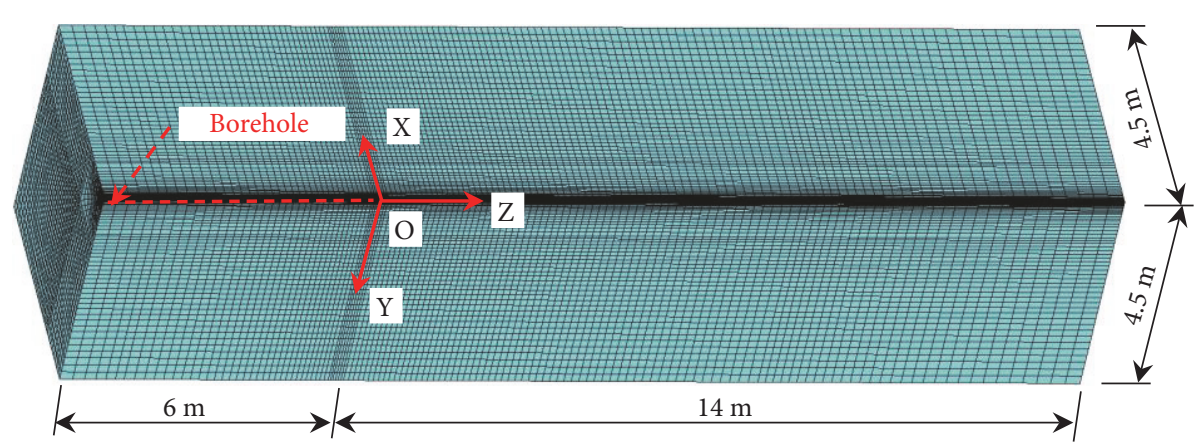

(a) Whole model

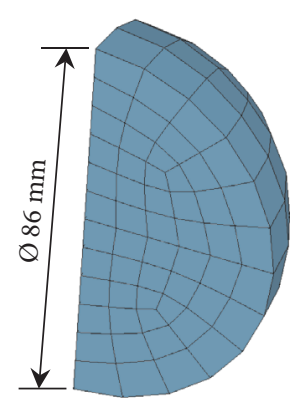

(b) Mesh of the spherical block

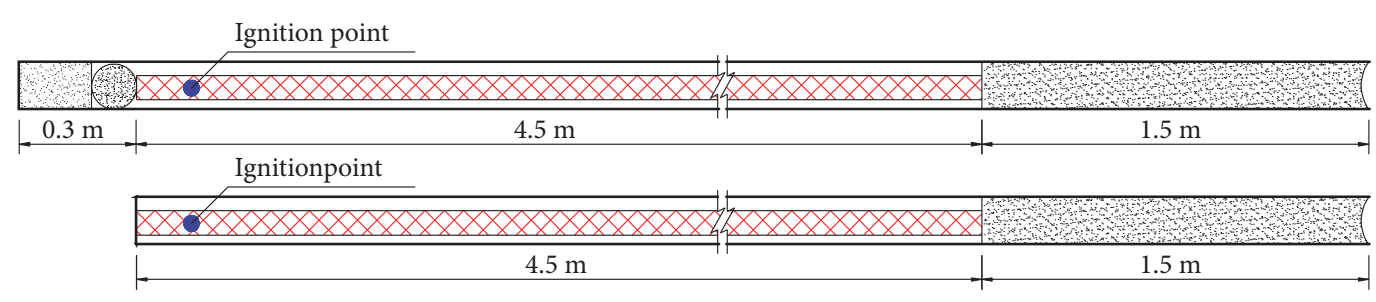

(c) Charge structure

FIGURE 12: Numerical simulation model. 
TABLE 6: Parameters values of the MAT_SOIL_AND _FOAM model.

\begin{tabular}{|c|c|c|c|}
\hline \multirow{2}{*}{ Material parameter } & & \multicolumn{2}{|c|}{ Pressure-volume strain curve } \\
\hline & & volume strain & Pressure $(\mathrm{MPa})$ \\
\hline \multirow{2}{*}{ Density $\left(\mathrm{Kg} / \mathrm{m}^{3}\right)$} & \multirow{2}{*}{1800} & 0.000 & 0.0 \\
\hline & & 0.104 & 0.2 \\
\hline \multirow{2}{*}{ Shear modulus (MPa) } & \multirow{2}{*}{0.639} & 0.161 & 0.4 \\
\hline & & 0.192 & 0.6 \\
\hline \multirow{2}{*}{ Bulk modulus (MPa) } & \multirow{2}{*}{0.3} & 0.224 & 1.2 \\
\hline & & 0.246 & 2.0 \\
\hline \multirow{2}{*}{ Tensile cutoff (MPa) } & \multirow{2}{*}{0} & 0.271 & 4.0 \\
\hline & & 0.283 & 6.0 \\
\hline \multirow{2}{*}{ Volumetric crushing option } & \multirow{2}{*}{0} & 0.290 & 8.0 \\
\hline & & 0.400 & 41 \\
\hline
\end{tabular}

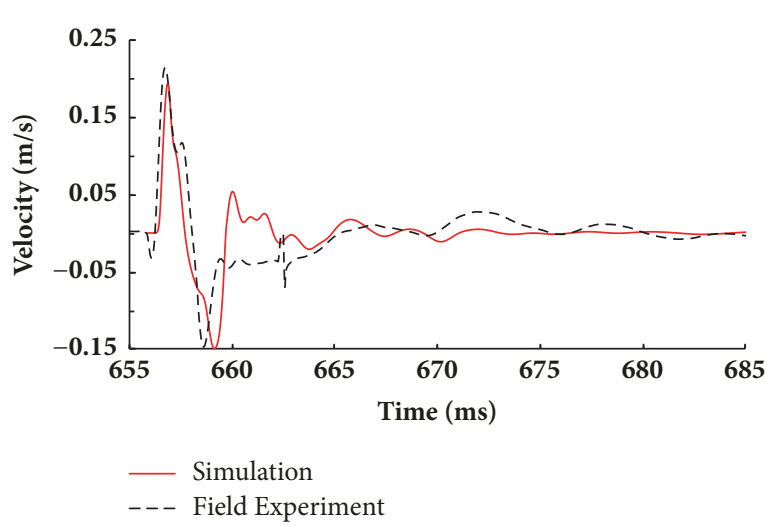

(a) Waveform

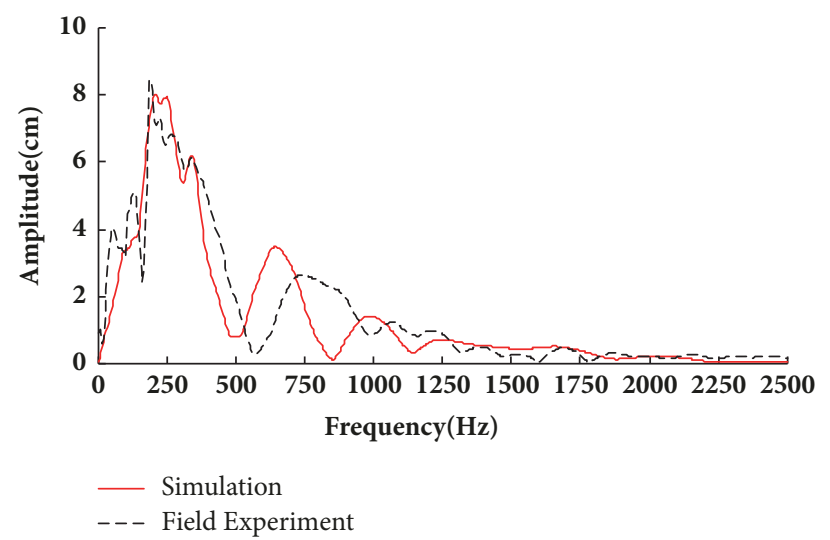

(b) Amplitude spectrum curve

FIGURE 13: Comparison of the waveforms and amplitude spectrum curves.

Coarse sand cushion material adopts MAT_SOIL_AND_ FOAM. This model can effectively simulate the liquefaction of sand under dynamic stress conditions. If the thermal effect is not taken into account in pressure versus volume strain behavior, the values of the parameters are shown in Table 6 [16].

4.2. Numerical Results. In order to justify the reliability of the numerical model, velocity-time waveforms and amplitude spectrum curves simulated in vertical borehole without the shock-reflection device are compared with field monitoring data at measurement point 2\#, as shown in Figure 13. It can be seen that the variation of simulated particle velocities is generally consistent with the monitoring data. The peak vibration value obtained by numerical simulation is 19.76 $\mathrm{cm} / \mathrm{s}$, which is very close to the measured peak vibration value of $21.47 \mathrm{~cm} / \mathrm{s}$. The trend of the whole waveform is also very close to that of the actual measured waveform. The main frequency of the calculated waveform is $205.4 \mathrm{~Hz}$, which is similar to the main frequency of the measured waveform of $189.8 \mathrm{~Hz}$, and the trend of the amplitude spectrum curve is also consistent. So, these all indicate that the simulation method, material models, and the material parameters used in this study are applicable to predict the vibration inside bench floor rock mass during blasting excavation.

Figure 14 shows the comparison of the PPV-distance curves of the blasting borehole with and without the shockreflection device calculated by the tensile-compressive damage model, and all the gauge points are located on the extension of the borehole axis. It shows that, under the given parameters described in Section 4.1, the vibration induced by the borehole with the shock-reflection is smaller than that without it. The vibration reduction factor is from $29.8 \%$ to $50.5 \%$, and the average vibration reduction factor is $41.1 \%$. It indicates that the shock-reflection device arranged at the bottom of bench blasting borehole has a significant effect on reducing the blasting induced vibration in the bench floor rock mass.

\section{Discussion}

Through the previous field experiment and numerical simulation results, it is shown that BSR makes an obvious contribution to reducing the blasting vibration velocity inside dam foundation rock mass. However, in hydropower projects presplitting blasting and smooth blasting are still common excavation methods for dam foundation excavation. 
TABLE 7: Comparison between different dam foundation protective layer excavation methods.

\begin{tabular}{|c|c|c|c|c|c|c|}
\hline \multirow{2}{*}{ Excavation method } & \multicolumn{2}{|c|}{ Overbreak/cm } & \multicolumn{2}{|c|}{ Underbreak/cm } & \multirow{2}{*}{$\mathrm{BDZ}$ depth/m } & \multirow{2}{*}{ Excavation speed } \\
\hline & Maximum & Average & Maximum & Average & & \\
\hline Smooth blasting & 41.6 & 7.3 & -5.8 & -2.9 & $0.68 \sim 0.71$ & Slow \\
\hline Presplitting blasting & 16.4 & 16.4 & -24.4 & -18.1 & $0.82 \sim 0.86$ & Moderate \\
\hline BSR & 25.7 & 5.4 & -13.3 & -5.6 & $0.74 \sim 0.79$ & Fast \\
\hline
\end{tabular}

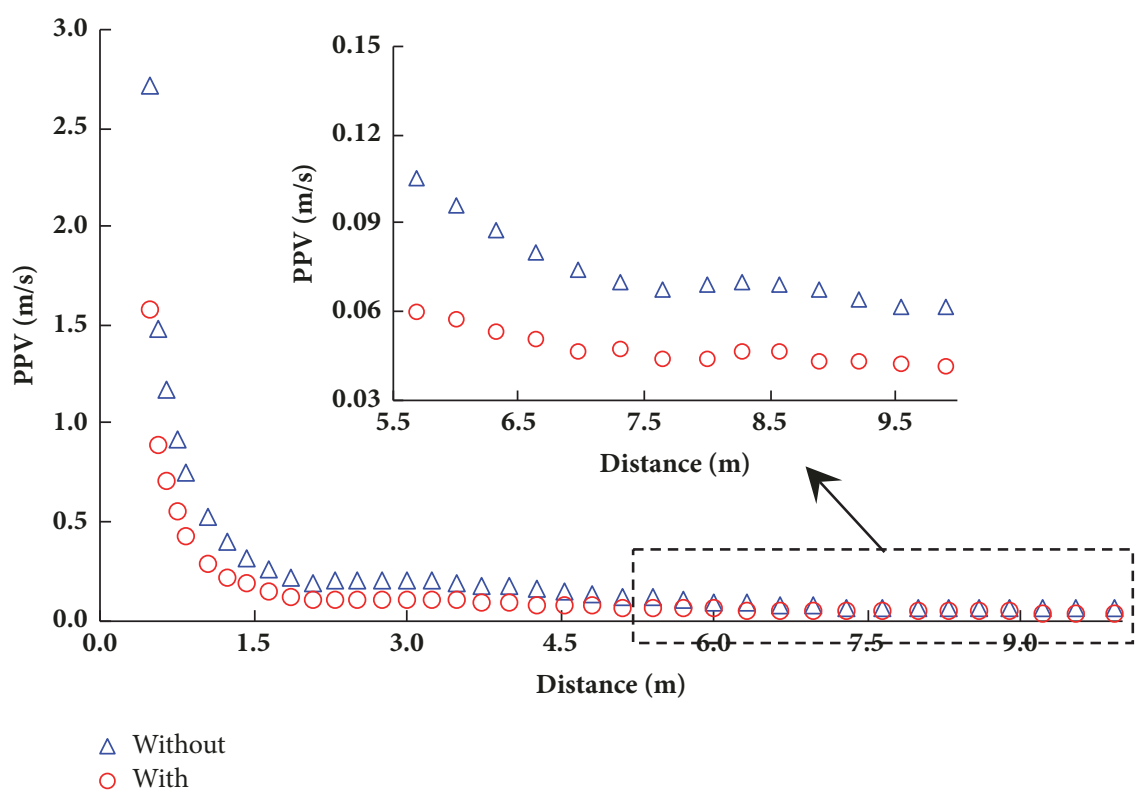

FIGURE 14: Comparison of the PPV-distance curves of the blasting borehole between with and without the device.

Therefore, it still needs large-scale production experiment to verify whether the BSR can be applied to the dam foundation excavation under complicated geological conditions of Baihetan Hydropower Station. The aim of dam foundation excavation is to create a contour following a predetermined form, thus the underbreak and overbreak of the excavation surface should meet the design requirements, with blastinduced damage strictly controlled $[17,18]$. Therefore, three experiment areas, BSR, presplitting, and smooth blasting, were designed in the production experiment. The overbeak, underbreak, blast-induced damage, and the vibration in the dam foundation rock mass were measured in each experiment area. The production experiments were implemented in the horizontal dam foundation excavation of Baihetan Hydropower Station. Rock masses here are typical columnar jointed basalts.

When the blasting is completed and the dam foundation surface is cleaned, to obtain the underbreak and overbreak values, four measurement control lines are arranged in each experiment zone. Measurement points are set every other 20 $\mathrm{cm}$ along these control lines. The underbreak and overbreak values can be obtained by measuring the elevations of the point.

In construction site of rock blasting and foundation excavation, sonic wave tests before and after rock blasting have been conducted in each test area. According to the construction technical code for excavating engineering of hydraulic structures, when the $\mathrm{P}$ wave transmission speed of the surface rock is decreased over $10 \%$ compared with the undisturbed rock mass, the rock is considered to be damaged. And the larger the ratio is, the greater the rock damage extent is. Therefore, four sonic monitoring holes are arranged in the middle of each experiment area, using the test method proposed by Lu et al. [19], and the depth of blast damage in each experiment area can be obtained.

The blasting vibration of the remaining rock mass under the foundation surface was monitored to evaluate the disturbance caused by different blasting techniques. Three vibration sensors at different distance below the foundation surface (1.0m below, $1.5 \mathrm{~m}$ below, and $2.0 \mathrm{~m}$ below) were embedded in the monitoring hole by cement paste as described in Section 3.

When the blasting is completed, the basic situation of dam foundation surface is shown in Figure 15. In the experiment site of BSR, spherical block made of high sonic impedance concrete was found after blasting, as shown in Figure 16. As can be seen from the photos, the spherical block was only slightly damaged.

Comparison between different dam foundation excavation methods is shown in Tables 7 and 8 . Table 7 shows that the overbreak and underbreak values of the three blasting techniques have little difference. The blast damage of presplitting blasting is more serious than that of BSR, and the damage depth of smooth blasting is the smallest. It can be seen from 
TABLE 8: PPV of different blasting techniques (unit: $\mathrm{cm} / \mathrm{s}$ ).

\begin{tabular}{lccccc}
\hline \multirow{2}{*}{ Vibration sensor } & \multirow{2}{*}{ BSR } & \multicolumn{2}{c}{ Presplitting blasting } & \multicolumn{2}{c}{ Smooth blasting } \\
& & Left & Right & Left & 15.3 \\
1.0m below & 11.2 & 20.0 & 35.1 & 11.3 \\
$1.5 \mathrm{~m}$ below & 9.5 & 25.6 & 20.5 & 10.7 & 7.9 \\
$2.0 \mathrm{~m}$ below & 3.1 & 24.1 & 16.1 & 11.7 & 7.6 \\
\hline
\end{tabular}

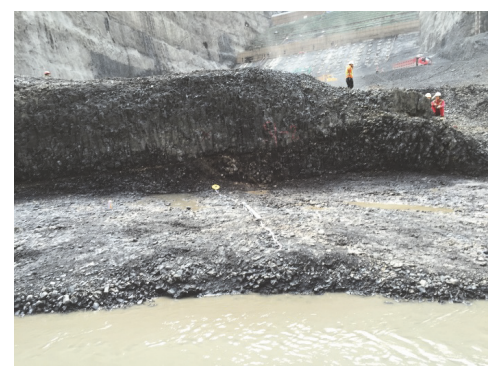

(a) BSR

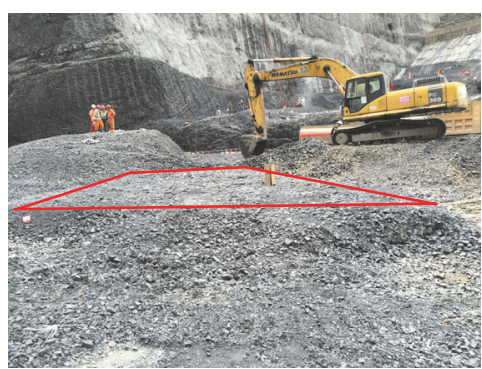

(b) Presplitting blasting

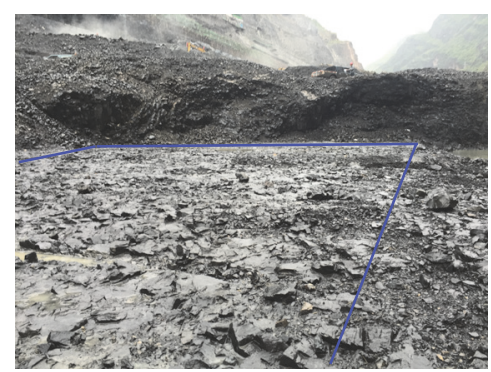

(c) Smooth blasting

FIGURE 15: Basic situation of dam foundation surface after blasting.

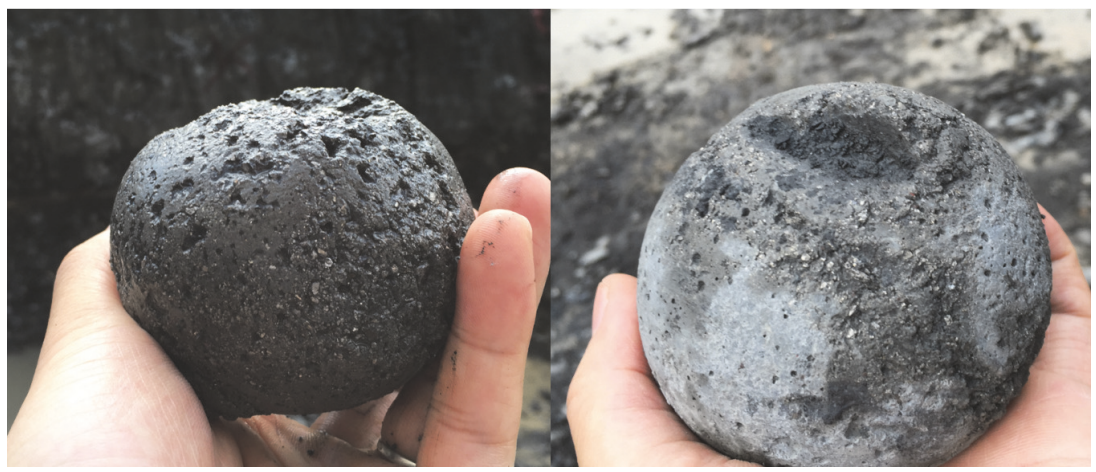

FIGURE 16: Spherical block after blasting.

Table 8 that the PPV caused by presplitting blasting is the largest among the three techniques. The blasting vibration of BSR and smooth blasting are roughly at the equal level within $1.5 \mathrm{~m}$. The contact surface between the BSR borehole and the dam foundation is only the borehole bottom, which is equivalent to the point load source, while those of the presplitting blasting and smooth blasting are the contacts of the contour blasting borehole wall with the dam foundation rock mass, which is equivalent to the area load source. Therefore, the decay rate induced by BSR is faster, which is very beneficial for reducing the vibration in dam foundation under complicated geological conditions.

It should be pointed out that, by using the BSRC, the vertical borehole can be fast drilled by the drilling machine, which is beneficial to save the drilling time. However, the horizontal borehole should be arranged in the smooth blasting and presplitting blasting construction, and the drilling process is complicated, which will seriously affect the construction speed of the blasting work. Under the premise of similar scale of the three experiment areas, the excavation work in the
BSR experiment area takes about 8 hours, in the presplitting blasting experiment area 12 hours, and in the smooth blasting experiment area 16 hours. Due to the large scale of dam foundation excavation at Baihetan Hydropower Station, the adoption of BSR will greatly increase the excavation progress and reduce the possibility of further relaxation of columnar jointed basalts over time.

Therefore, from the perspectives of both reducing the vibration and increasing construction efficiency, the BSR is suitable for Baihetan complicated geological dam foundation excavation. The excavation area of right bank dam foundation has reached 8,000 square meters and that of left bank 13,000 square meters, and the dam foundation excavation task was completed 20 days earlier than expected.

\section{Conclusions}

The bench blasting with cushion at borehole bottom has been improved: a special shock-reflection device is installed at the vertical borehole bottom to control blasting vibration. 
Through theoretical analysis and blasting vibration numerical simulation based on ANSYS/LS-DYNA, combined with field experiments, the following results are achieved:

(1) The shock-reflection device is a combination of spherical block made up of high sonic impedance concrete or cast iron and flexible cushion made up of coarse sand. The spherical block reflects the shock wave and the flexible cushion can provide buffering effect, both of which can noticeably achieve vibration reducing effect in the foundation rock mass.

(2) The vibration numerical simulation shows that the vibration induced by the borehole with the device is between $29.8 \%$ and $50.5 \%$, smaller than the borehole without the structure, which is consistent with the results of field experiment, from $29.8 \%$ to $56.5 \%$.

(3) It is proven through production experiments that, within the depth of $1.5 \mathrm{~m}$, the vibration of dam foundation rock mass using BSR is less than the presplitting blasting and near smooth blasting. Also it can acquire a faster vibration decay rate, which is beneficial for reducing the vibration among dam foundations under complicated geological conditions.

\section{Data Availability}

The data used to support the findings of this study are available from the corresponding author upon request.

\section{Conflicts of Interest}

The authors declare that there are no conflicts of interest regarding the publication of this paper.

\section{Acknowledgments}

This work is supported by Chinese National Science Fund (51779190). The authors wish to express their thanks to the supporter.

\section{References}

[1] M. Khandelwal and T. N. Singh, "Evaluation of blast-induced ground vibration predictors," Soil Dynamics and Earthquake Engineering, vol. 27, no. 2, pp. 116-125, 2007.

[2] C. Kuzu, "The importance of site-specific characters in prediction models for blast-induced ground vibrations," Soil Dynamics and Earthquake Engineering, vol. 28, no. 5, pp. 405-414, 2008.

[3] D. Ainalis, O. Kaufmann, J.-P. Tshibangu, O. Verlinden, and G. Kouroussis, "Modelling the Source of Blasting for the Numerical Simulation of Blast-Induced Ground Vibrations: A Review," Rock Mechanics and Rock Engineering, vol. 50, no. 1, pp. 1-23, 2016.

[4] M. Chen, J. Zhang, W. Lu, P. Yan, and K. Deng, "Influence of Blasting Vibration on Young Concrete Bridge: A Case Study of Yesanhe Super Large Bridge," Shock and Vibration, vol. 2017, 2017.

[5] A. Gudmundsson, "Magma chambers: formation, local stresses, excess pressures, and compartments," Journal of Volcanology and Geothermal Research, vol. 237-238, pp. 19-41, 2015.
[6] A. Gudmundsson and I. F. Løtveit, "Sills as fractured hydrocarbon reservoirs: examples and models," Geological Society of London Special Publications, vol. 374, no. 1, pp. 251-271, 2014.

[7] C. H. Dowding and C. T. Aimone, "Multiple blast-hole stresses and measured fragmentation," Rock Mechanics and Rock Engineering, vol. 18, no. 1, pp. 17-36, 1985.

[8] A. T. Edwards and T. D. Northwood, "Experimental Studies of the effects of blasting on structures," Engineering, vol. 210, pp. 538-546, 1960.

[9] W.-B. Lu, Y. Luo, M. Chen, and D.-Q. Shu, "An introduction to Chinese safety regulations for blasting vibration," Environmental Earth Sciences, vol. 67, no. 7, pp. 1951-1959, 2012.

[10] Y. Zhang, W. Lu, M. Chen, P. Yan, and Y. Hu, "Dam foundation excavation techniques in China: a review," Journal of Rock Mechanics and Geotechnical Engineering, vol. 5, no. 6, pp. 460467, 2013.

[11] Y.-Z. Hu and G.-P. Xu, "Experimental study on excavating protective layer by horizontal presplitting method," Blasting, vol. 17, pp. 18-20, 2000.

[12] J. Achenbach, Wave Propagation in Elastic Solids, North-holland Pub. Co., London, England, 1973.

[13] H. Hu, W. Lu, P. Yan, M. Chen, Q. Gao, and Z. Yang, "A new horizontal rock dam foundation blasting technique with a shockreflection device arranged at the bottom of vertical borehole," European Journal of Environmental and Civil Engineering, pp. 1-19, 2017.

[14] Y. G. Hu, W. Lu, M. Chen, P. Yan, and J. Yang, "Comparison of blast-induced damage between presplit and smooth blasting of high rock slope," Rock Mechanics and Rock Engineering, vol. 47, no. 4, pp. 1307-1320, 2014.

[15] J. A. Sanchidrián, R. Castedo, L. M. López, P. Segarra, and A. P. Santos, "Determination of the JWL constants for ANFO and emulsion explosives from cylinder test data," Central European Journal of Energetic Materials, vol. 12, no. 2, pp. 177-194, 2015.

[16] J. Li, M.-S. Li, H. Li, and C.-C. Shi, "Numerical modeling of projectile penetration into dry sand," Combustion, Explosion, and Shock Waves, vol. 35, pp. 633-640, 2015.

[17] S. K. Mandal, M. M. Singh, and S. Dasgupta, "Theoretical concept to understand plan and design smooth blasting pattern," Geotechnical and Geological Engineering, vol. 26, no. 4, pp. 399416, 2008.

[18] S. S. Rathore and S. Bhandari, "Controlled fracture growth by blasting while protecting damages to remaining rock," Rock Mechanics and Rock Engineering, vol. 40, no. 3, pp. 317-326, 2007.

[19] W.-B. Lu, Y.-G. Hu, J.-H. Yang, M. Chen, and P. Yan, "Spatial distribution of excavation induced damage zone of high rock slope," International Journal of Rock Mechanics and Mining Sciences, vol. 64, pp. 181-191, 2013. 


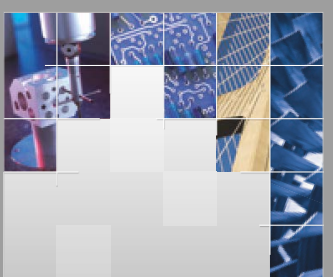

\section{Enfincering}
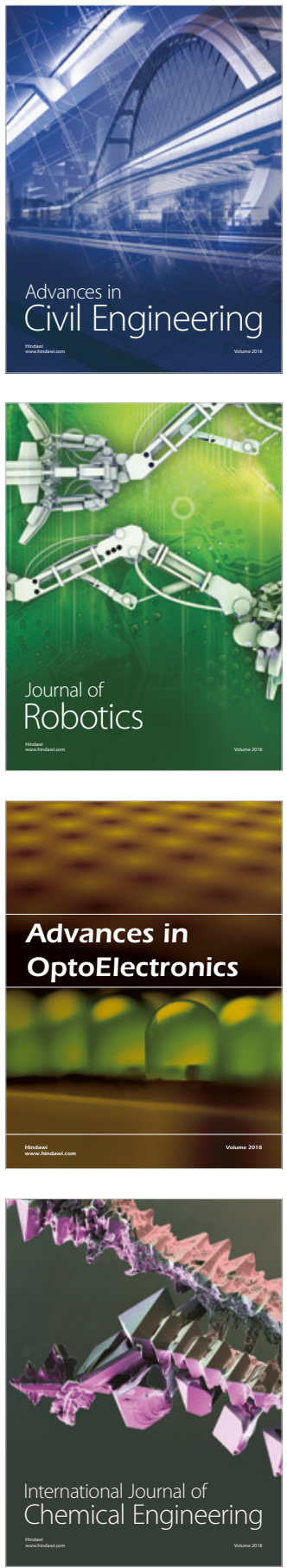

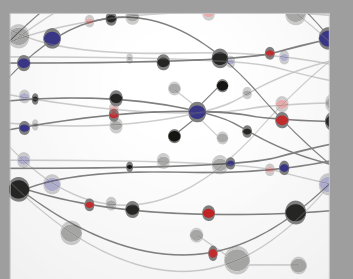

\section{Rotating \\ Machinery}

The Scientific World Journal

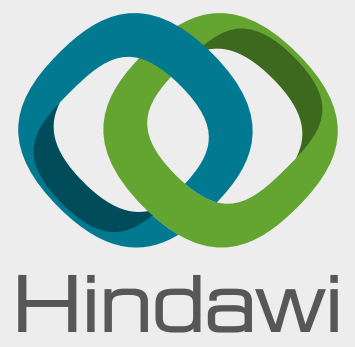

Submit your manuscripts at

www.hindawi.com
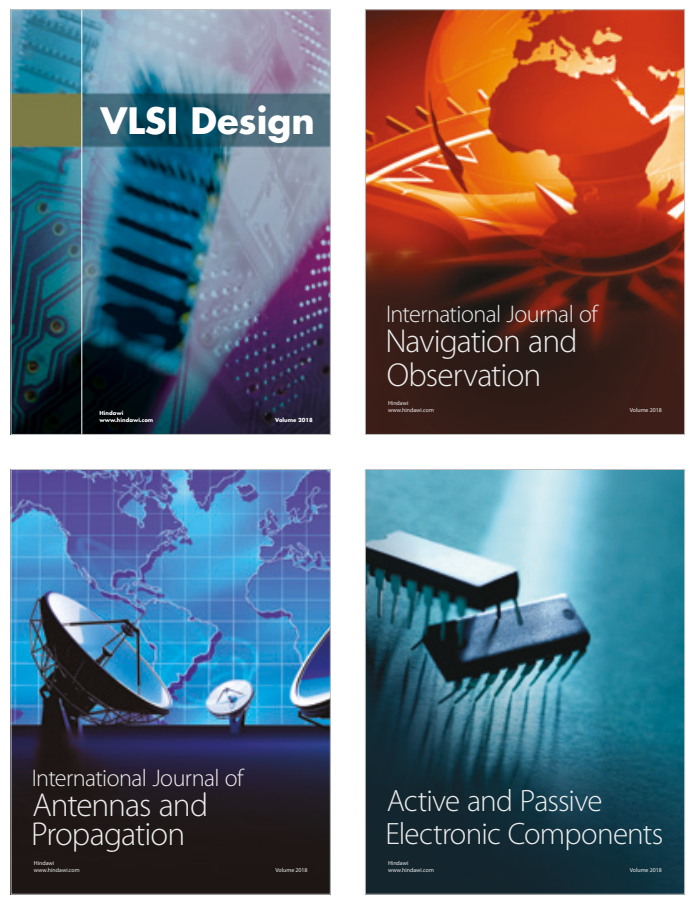
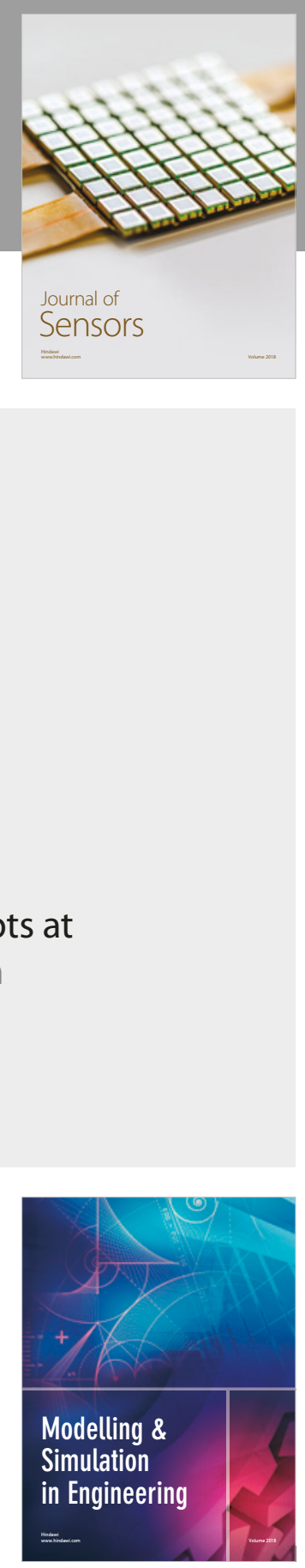

\section{Advances \\ Multimedia}
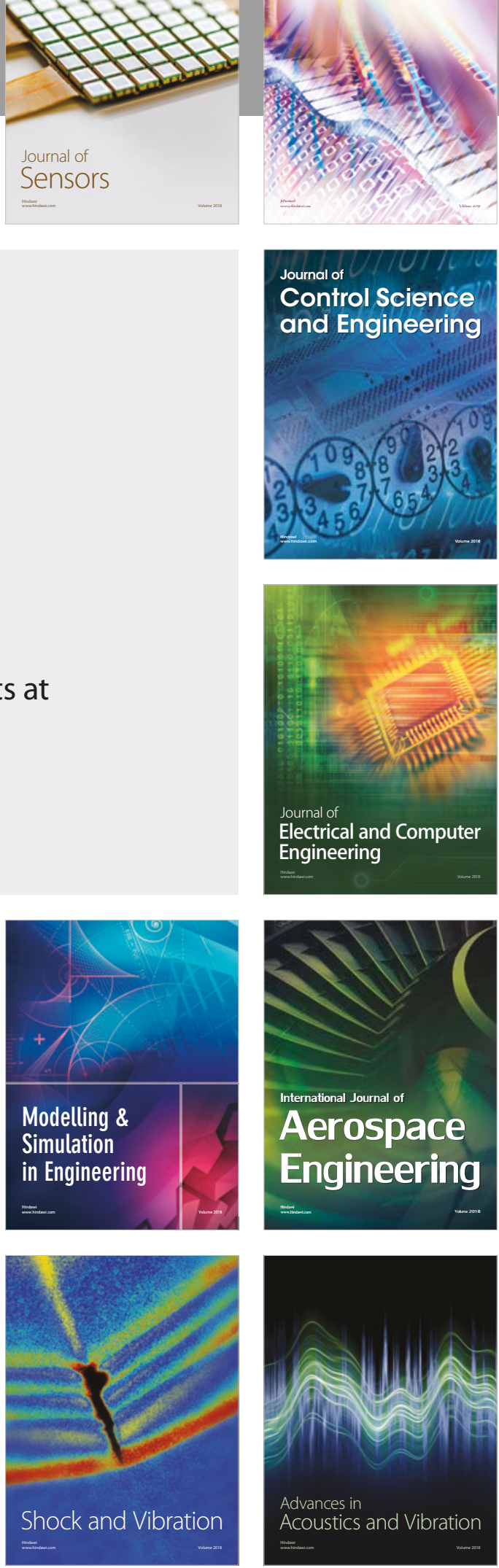